\title{
Preparation and Characterization of Talc Filled Thermoplastic Polyurethane/Polypropylene Blends
}

\author{
Emi Govorčin Bajsić, ${ }^{1}$ Vesna Rek, ${ }^{1}$ and Ivana Ćosić ${ }^{2}$ \\ ${ }^{1}$ Department of Polymer Engineering and Organic Chemical Technology, Faculty of Chemical Engineering and Technology, \\ University of Zagreb, Marulićev trg 19, 10000 Zagreb, Croatia \\ ${ }^{2}$ Department of Industrial Ecology, Faculty of Chemical Engineering and Technology, University of Zagreb, Marulićev trg 19, \\ 10000 Zagreb, Croatia
}

Correspondence should be addressed to Emi Govorčin Bajsić; egovor@fkit.hr

Received 1 December 2013; Accepted 21 January 2014; Published 3 March 2014

Academic Editor: Yves Grohens

Copyright (C) 2014 Emi Govorčin Bajsić et al. This is an open access article distributed under the Creative Commons Attribution License, which permits unrestricted use, distribution, and reproduction in any medium, provided the original work is properly cited.

\begin{abstract}
The effect of the addition of talc on the morphology and thermal properties of blends of thermoplastic polyurethane (TPU) and polypropylene (PP) was investigated. The blends of TPU and PP are incompatible because of large differences in polarities between the nonpolar crystalline PP and polar TPU and high interfacial tensions. The interaction between TPU and PP can be improved by using talc as reinforcing filler. The morphology was observed by means of scanning electron microscopy (SEM). The thermal properties of the neat polymers and unfilled and talc filled TPU/PP blends were studied by using dynamic mechanical analysis (DMA), differential scanning calorimetry (DSC), and thermogravimetric analysis (TGA). The addition of talc in TPU/PP blends improved miscibility in all investigated TPU/T/PP blends. The DSC results for talc filled TPU/PP blends show that the degree of crystallinity increased, which is due to the nucleating effect induced by talc particles. The reason for the increased storage modulus of blends with the incorporation of talc is due to the improved interface between polymers and filler. According to TGA results, the addition of talc enhanced thermal stability. The homogeneity of the talc filled TPU/PP blends is better than unfilled TPU/PP blends.
\end{abstract}

\section{Introduction}

Blending has been widely and effectively used to modify or control the properties of polymer by appropriately compounding miscible polymers. Miscible polymer blends can create new materials with completely different properties, and fabricated articles may possess good mechanical properties. Thermoplastic polyurethanes (TPUs) are linear, segmented copolymers consisting of alternating hard segments (HSs) and soft segments (SSs). HSs, comprised of diisocyanate and short chain extender (CE) molecules such as diols or diamines, are rigid and highly polar. HSs have high interchain interaction due to hydrogen bonding between the urethane/urea groups. The hydrogen bonding associations within the HSs in TPUs act as a reinforcing filler for the soft matrix. On the other hand, SSs, formed from linear long-chain diols or polyols, are flexible and weakly polar [1]. Phase separation in TPUs occurs because of the thermodynamic immiscibility or incompatibility between the hard and soft phase. The degree of phase separation in Pus depends on the types of diisocyanate and polyol and polyol employed to produce the PU, type of polyfunctional compound used in the crosslinking process, $\mathrm{NCO}: \mathrm{OH}$ ratio, size of HSs and SSs, and method of synthesis. Polypropylene (PP), a semicrystalline polyolefin polymer with very interesting mechanical properties (ductility and stiffness), good thermal properties, and excellent chemical and moisture resistance is also easy to process. Limitation of PP is its poor adhesion to the surface of other phases such as rubber or polar materials. This is primarily a result of the nonpolar nature of $\mathrm{PP}[2,3]$. The incorporation of proper filler increase interfacial adhesion between matrix and disperse phase refines blends morphology and therefore leads to 
an improvement of processing and application properties of the final material. Traditional fillers for PP are calcium carbonate, talc, glass fiber, wollastonite, mica, glass beads, and wood flour. Filled PP containing talc is used extensively because of a combination of stiffness, dimensional stability, and, importantly, low cost. It is well known that mineral fillers increase the rigidity of the polymers, but they also decrease ductility and toughness [4]. In studying the complex structure and morphology of polymers modified by mineral fillers, some problems may arise concerning the character and extent of interaction at the polymer-filler interface, the homogeneity of filler distribution, the filler orientation in the case of filler anisometric particles, and the polymer-filler adhesion [5]. The talc filled TPU/PP blends can be processed by injection molding, which is a common method to make products from thermoplastics. The properties of the molded product depend on the nature of the filler, its concentration, and the molding conditions. The most important characteristics of the filler are its size, shape and its ability to act as nucleating agent for crystallization [5].

\section{Materials and Methods}

2.1. Materials. Thermoplastic polyurethane (TPU, Desmopan $588 \mathrm{E}$ a polyester-polyether type, Bayer A.G., Germany), isotactic polypropylene (i-PP, Moplen HP 500N, Basel Polyolefines, Basel, Switzerland with $\mathrm{MFI}=12 \mathrm{~g} / 10 \mathrm{~min}$ at $190^{\circ} \mathrm{C}$ ), talc (Luzenac $10 \mathrm{MO}$, Solvay, France), with platelet diameter $(400 \mathrm{~nm})$, specific surface $\left(6.50 \mathrm{~m}^{2} \mathrm{~g}^{-1}\right)$, and density $\left(2.8 \mathrm{~g} \mathrm{~cm}^{-3}\right)$.

2.2. Preparation of Blends. The TPU/PP blends without talc (TPU/PP: $80 / 20,50 / 50$, and 20/80 blends) and with $5 \mathrm{wt} \%$ of talc (TPU/T/PP: 80/5/20, 50/5/50, and 20/5/80 blends) were prepared by melt blending using a Rondol $21 \mathrm{~mm}$ LAB TWIN twin-screw extruder. Before processing, the talc was added to the TPU and PP pellets and the components were mixed and charged into the twin-screw extruder. The temperatures in the extruder were set to $170^{\circ} \mathrm{C}, 180^{\circ} \mathrm{C}, 180^{\circ} \mathrm{C}, 200^{\circ} \mathrm{C}$, and $200^{\circ} \mathrm{C}$, the temperature of the die was $200^{\circ} \mathrm{C}$, the screw speed was $60 \mathrm{rpm}$, and the torque was between 60 and $95 \%$. Extrudates were cooled in a water bath, pulled, and pelletized. Injection moulding was done using a Rondol, High Force 5 injection press to produce test specimens at $180^{\circ} \mathrm{C}$.

2.3. Characterization. The viscoelastic properties of the neat TPU, PP; TPU/T, and PP/T composites as well as TPU/PP blends, also the miscibility of the TPU/PP blends, were carried out with a Dynamic Mechanical Analyser DMA 983 (TA Instruments, USA) at a frequency of $1 \mathrm{~Hz}$.

The changes of storage $\left(E^{\prime}\right)$ and loss $\left(E^{\prime \prime}\right)$ moduli were measured over the temperature range of -100 to $250^{\circ} \mathrm{C}$ at a heating rate of $3^{\circ} \mathrm{C} / \mathrm{min}$. The sample length between the clamps was approximately $25 \mathrm{~mm}$.

The crystallization behavior of neat polymers (TPU, $\mathrm{PP}$ ) and TPU/PP and TPU/T/PP blends were studied by differential scanning calorimetry (Mettler Toledo DSC $822^{\mathrm{e}}$, Switzerland) under nitrogen flow $(40 \mathrm{~mL} / \mathrm{min})$. DSC was calibrated with indium standard prior to use. The thermal cycling applied was that samples were heated to $190^{\circ} \mathrm{C}$ at a heating rate of $10^{\circ} \mathrm{C} / \mathrm{min}$, annealed at $190^{\circ} \mathrm{C}$ for $10 \mathrm{~min}$ in order to eliminate any previous thermal history, and then quenched with liquid nitrogen to $-100^{\circ} \mathrm{C}$ and heated to $190^{\circ} \mathrm{C}$. From the second heating run, the melting enthalpy $\left(\Delta H_{m}\right)$ and crystallization enthalpy $\left(\Delta H_{c}\right)$ were obtained. The TPU/PP and TPU/T/PP blend samples were sliced from injection-moulded specimens, a sample weight of approximately $10 \mathrm{mg}$ was used.

The degree of crystallinity, $\chi_{c}$, was calculated by comparing the measured melting heat to melting heat of $100 \%$ crystalline iPP (1):

$$
\chi_{c}=\frac{\Delta H_{m}}{\Delta H_{\mathrm{PP}}^{0}} \times 100,
$$

where $\Delta H_{m}$ is the enthalpy of malting and $\Delta H_{\mathrm{PP}}^{0}$ enthalpy of malting for completely crystalline PP, equal to $165 \mathrm{~J} / \mathrm{g}[6,7]$.

In order to assess the thermal stability of the neat TPU, PP; TPU/T and PP/T composites and TPU/PP blends were characterized by thermogravimetric analysis (TGA) (Q500, TA Instruments, USA). The sample (about $10 \mathrm{mg}$ ) was loaded on the pan and heated from room temperature to $700^{\circ} \mathrm{C}$ at a heating rate of $10^{\circ} \mathrm{C} / \mathrm{min}$ under nitrogen flow $(60 \mathrm{~mL} / \mathrm{min})$.

A Vega 3 Tescan scanning electron microscope (Brno, Czech Republic) was used to study the morphology. Samples were fractured in liquid nitrogen and the fracture surface was coated with gold before being examined with the microscope.

\section{Results and Discussion}

The viscoelastic properties of the neat TPU, PP: TPU/T, PP/T composites and TPU/PP blends were characterized using the dynamic mechanical analysis (DMA). The temperature dependence of the storage $\left(E^{\prime}\right)$ and loss moduli $\left(E^{\prime \prime}\right)$ for neat TPU, PP and TPU/T, PP/T composites are presented in Figures 1(a) and 1(b), respectively. The experimental results are listed in Table 1. The temperature associated with the peak maximum of $E^{\prime \prime}$ corresponds to the glass transition temperature $\left(T_{g}\right)$ of TPU and PP. The $E^{\prime \prime} / T$ curve for the neat TPU shows the $T_{g}$ of the soft segments of the polyurethane at $-27.3^{\circ} \mathrm{C}[8,9]$ and this value increases by adding talc (from -27.3 to $-21.7^{\circ} \mathrm{C}$ ) (Figure $1(\mathrm{~b})$, Table 1 ). The value of $T_{g}$ of a polymer depends on the macromolecule chain segment mobility in the polymer matrix. The presence of talc restricted the mobility of the molecular chain of TPU, and so $T_{g}$ increases as a consequence of interactions between talc and the TPU chains. In the case of PP and PP/T composite, $E^{\prime \prime}$ showed three distinct relaxations (Figure 1(b), Table 1). The maxima on relaxation peak at $24.3^{\circ} \mathrm{C}$ could be ascribed to the glass transition $\left(T_{g}\right)$ of the PP amorphous phase [10], at $-44.3^{\circ} \mathrm{C}$ the $\gamma$-relaxation of the PP appears associated with the motions of small-chain groups like methyl and methylene [11], and another relaxation at higher temperatures appears, $\alpha_{C}$ relaxation shoulder (at approximately $57.2^{\circ} \mathrm{C}$ ), and could be related to a more rigid chain with an amorphous character related to the PP crystallites (tie molecules, etc.). 


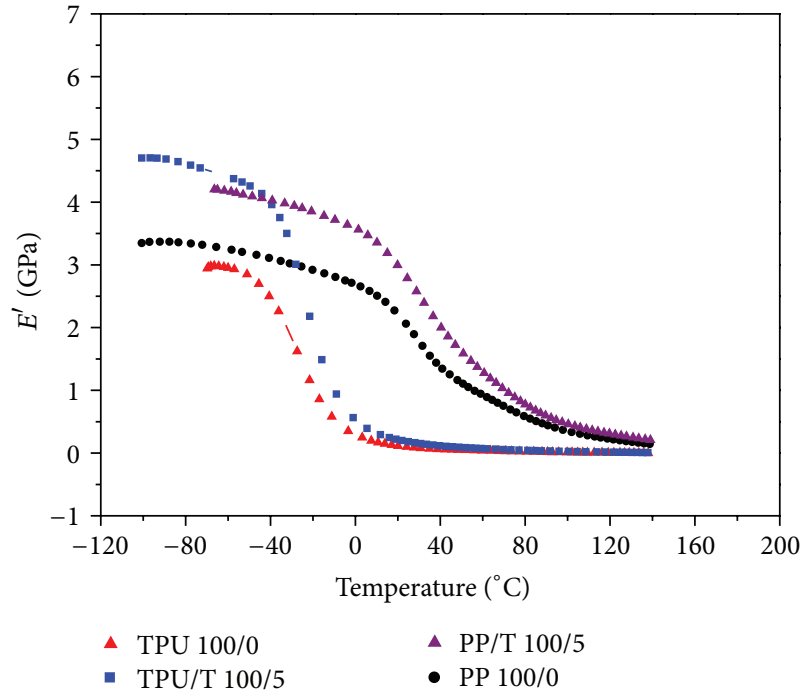

(a)

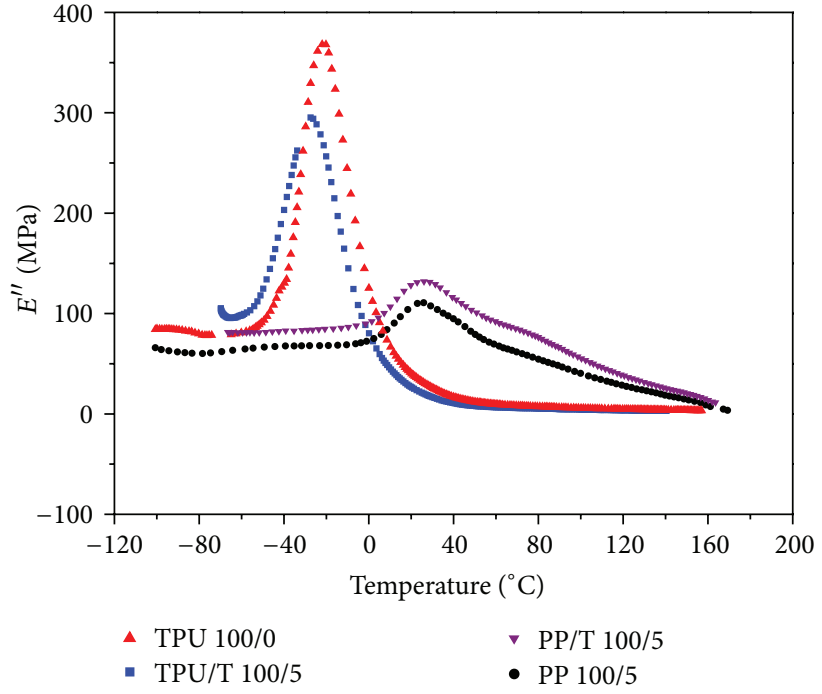

(b)

Figure 1: Plot of (a) storage modulus $\left(E^{\prime}\right)$ and (b) loss modulus $\left(E^{\prime \prime}\right)$ for the neat TPU, PP and TPU/T and PP/T composites.

TABLE 1: DMA results of the neat TPU, PP, TPU/T and PP/T composites, and unfilled and talc filled TPU/PP blends.

\begin{tabular}{lcccc}
\hline Sample & $T_{g, \text { TPU }}\left({ }^{\circ} \mathrm{C}, E^{\prime \prime}\right)$ & $T_{g, \text { PP }}\left({ }^{\circ} \mathrm{C}, E^{\prime \prime}\right)$ & $E^{\prime}(\mathrm{GPa})$ at $25^{\circ} \mathrm{C}$ & $\alpha_{c}\left({ }^{\circ} \mathrm{C}\right)$ \\
\hline TPU 100/0 & -27.3 & - & 0.1 & - \\
TPU/T 100/5 & -21.7 & - & 0.2 & - \\
PP 100/0 & - & 24.3 & 2.3 & 57.2 \\
PP/T 100/5 & - & 26.4 & 2.8 & 69.4 \\
TPU/PP 80/20 & -22.2 & - & 0.2 & - \\
TPU/T/PP 80/5/20 & -21.1 & - & 0.5 & - \\
TPU/PP 50/50 & -21.2 & 16.6 & 1.0 & 72.3 \\
TPU/T/PP 50/5/50 & -18.0 & 18.2 & 1.2 & 77.0 \\
TPU/PP 20/80 & -26.7 & 20.7 & 1.9 & 75.3 \\
TPU/T/PP 20/5/80 & -20.3 & 22.5 & 2.0 & 76.7 \\
\hline
\end{tabular}

The transition temperatures obtained in the DMA measurements of the investigated unfilled and talc filled TPU/PP blends with different TPU/PP content are shown in Figure 2 and summarized in Table 1 . Figure 2(a) shows the temperature dependency of $E^{\prime \prime}$ for unfilled and talc filled TPU/PP blends, in which the two distinct relaxations observed corresponded to the $T_{g}$ of TPU and $T_{g}$ of PP at all compositions except for the TPU/PP 80/20 blends. Compared with the neat TPU and PP, the $T_{g}$ of TPU shifted to higher temperatures and the $T_{g}$ of $\mathrm{PP}$ shifted to lower temperatures for the TPU/PP and TPU/T/PP blends and the maximum peaks broader.

This might be explained with a lower segmental mobility which is suppressed by the crystalline phase of PP and with filler.

In the case of talc filled blends (TPU/T/PP blends), the addition of talc in the blends the $T_{g}$ maxima of the TPU and PP shift towards to each other. This result may be related to the same interaction in the blends due to the presence of talc, which caused better interphase for both polymers [11, 12].
Figure 2(b) shows the temperature dependence of the storage modulus $\left(E^{\prime}\right)$ for neat polymers, composites, unfilled, and talc filled TPU/PP blends. The results for all investigated samples at $25^{\circ} \mathrm{C}$ are listed in Table 1 . As shown in Figure 2(b) the $E^{\prime}$ of the neat TPU and TPU/T composite decreased sharply in the $T_{g}$ region due to the mobility of the soft segments. The results shown in Table 1 indicate that in the measured region, the $E^{\prime}$ of the neat PP was higher than that of the neat TPU and at $25^{\circ} \mathrm{C}$ a value of TPU $(0.08 \mathrm{GPa})$ is much lower than that of the neat PP $(2.87 \mathrm{GPa})$. In all prepared blends, the $E^{\prime}$ have intermediate value of the neat TPU and PP. The values of E' of blends increased with increasing PP content in blends and with the addition of talc. These results may be caused by an interaction between the TPU and PP, as well as interactions with talc particles.

Figure 3 shows DSC thermograms for unfilled and talc filled TPU/PP blends and the corresponding values are summarized in Table 2.

It can be observed from Table 2 that the melting temperatures $\left(T_{m}\right)$ of the TPU/PP blends do not change with 

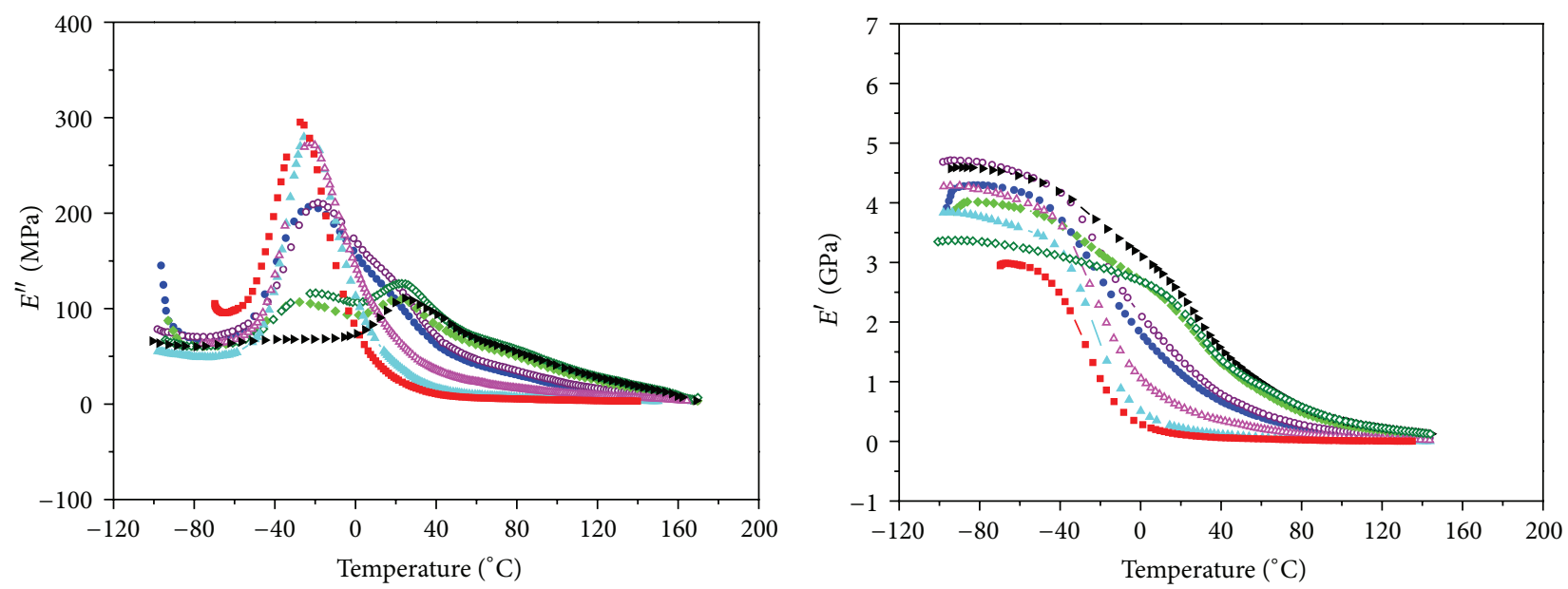

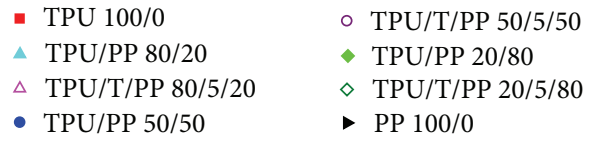

(a)

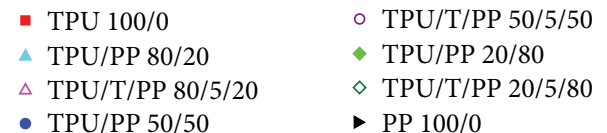

(b)

Figure 2: Plot of (a) loss modulus $\left(E^{\prime \prime}\right)$ and (b) storage modulus $\left(E^{\prime}\right)$ of unfilled and talc filled TPU/PP blends.

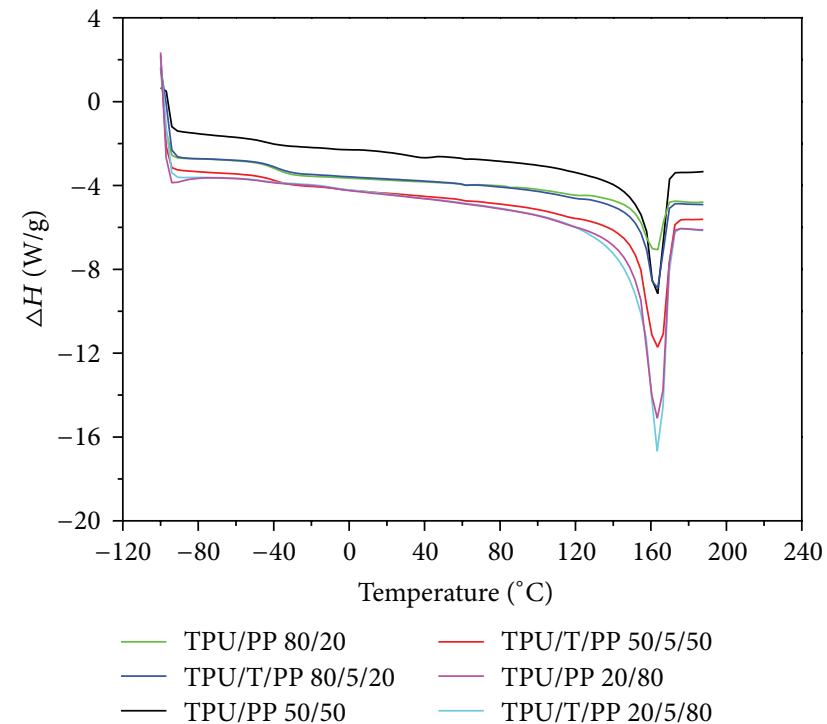

(a)

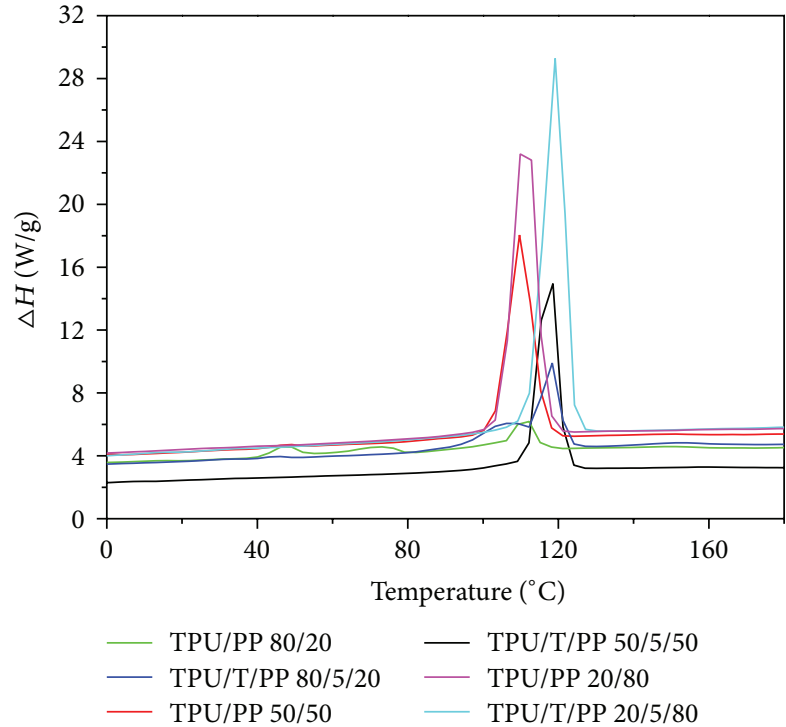

(b)

FIGURE 3: DSC heating (a) and crystallization (b) curves of unfilled and talc filled TPU/PP blends.

TABLE 2: Thermal properties of the unfilled and talc filled TPU/PP blends.

\begin{tabular}{lccccc}
\hline Sample & $T_{m}\left({ }^{\circ} \mathrm{C}\right)$ & $T_{\mathrm{cp}}\left({ }^{\circ} \mathrm{C}\right)$ & $\Delta H_{m}(\mathrm{~J} / \mathrm{g})$ & $\Delta H_{c}(\mathrm{~J} / \mathrm{g})$ & 9.3 \\
\hline TPU/PP 80/20 & 163.4 & 111.4 & 15.0 & 24.0 & 9.1 \\
TPU/T/PP 80/5/20 & 163.0 & 118.1 & 24.0 & 45.8 & 14.5 \\
TPU/PP 50/50 & 164.3 & 110.0 & 42.1 & 53.8 & 25.5 \\
TPU/T/PP 50/5/50 & 163.0 & 117.5 & 46.6 & 77.4 & 28.2 \\
TPU/PP 20/80 & 164.3 & 111.3 & 74.1 & 79.8 \\
TPU/T/PP 20/5/80 & 164.0 & 120.0 & 77.9 & 45.0 \\
\hline
\end{tabular}




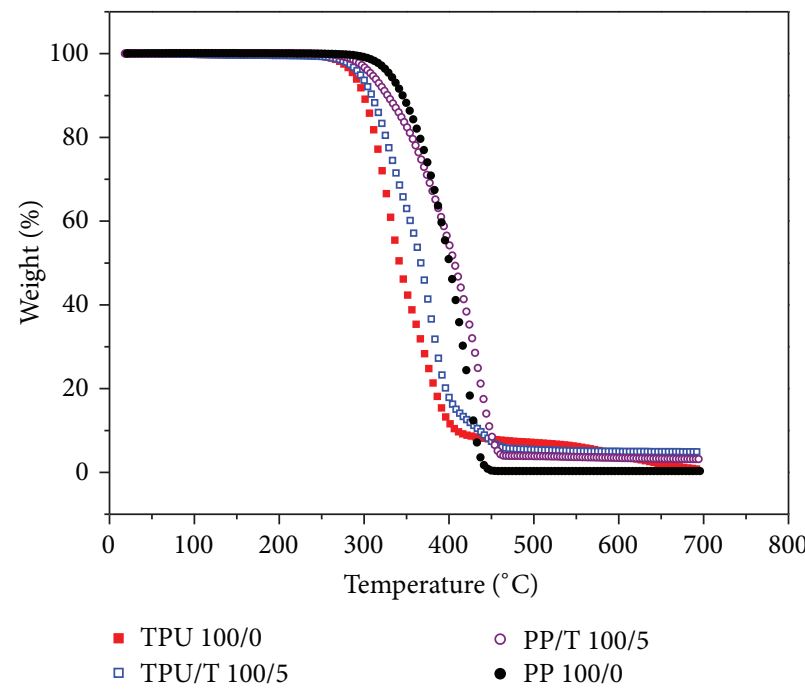

(a)

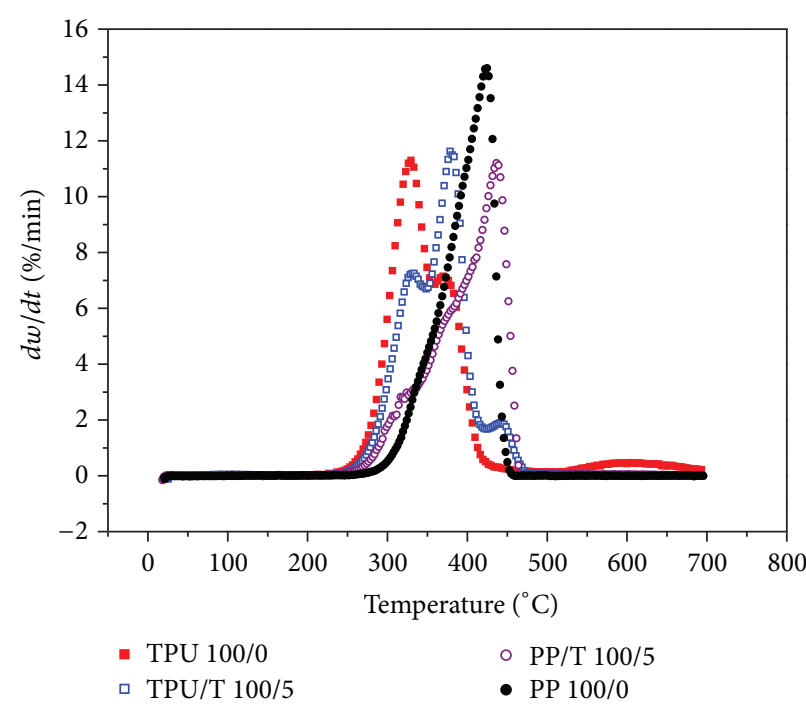

(b)

Figure 4: TG curves (a) and DTG curves (b) of the neat TPU, PP and TPU/T and PP/T composites.

TABLE 3: Results of TGA measurement for the neat TPU, PP, TPU/T and PP/T composites, and unfilled and talc filled TPU/PP blends.

\begin{tabular}{lccccccccccc}
\hline Sample & $T_{5}\left({ }^{\circ} \mathrm{C}\right)$ & $T_{1}^{\max }\left({ }^{\circ} \mathrm{C}\right)$ & $\Delta_{m 1}(\%)$ & $T_{2}^{i}\left({ }^{\circ} \mathrm{C}\right)$ & $T_{2}^{\max }\left({ }^{\circ} \mathrm{C}\right)$ & $\Delta_{m 2}(\%)$ & $T_{3}^{i}\left({ }^{\circ} \mathrm{C}\right)$ & $T_{3}^{\max }\left({ }^{\circ} \mathrm{C}\right)$ & $\Delta_{m 3}(\%)$ & $T_{\text {end }}\left({ }^{\circ} \mathrm{C}\right)$ & $\begin{array}{l}\mathrm{Residue} \text { at } \\
700\end{array}$ \\
\hline TPU 100/0 & 288.1 & 328.8 & 62.3 & 357.6 & 369.8 & 30.2 & - & - & - & 400.4 \\
TPU/T 100/5 & 295.6 & 331.1 & 34.3 & 348.2 & 380.0 & 53.4 & 425.4 & 441.3 & 6.5 & 458.4 \\
PP 100/0 & 312.3 & 423.9 & 99.7 & - & - & - & - & - & - & 437.7 & 0.7 \\
PP 100/5 & 330.7 & 435.5 & 96.4 & - & - & - & - & - & - & 455.5 & 3.9 \\
$80 / 20$ & 299.6 & 337.2 & 44.1 & 352.2 & 368.9 & 51.7 & - & - & 10.4 & - & 2.8 \\
80/5/20 & 300.0 & 337.8 & 33.0 & 347.2 & 378.3 & 45.9 & 421.2 & 430.4 & 15.2 & 451.5 & 5.0 \\
$50 / 50$ & 301.7 & 318.7 & 18.3 & 347.5 & 388.7 & 39.4 & 413.2 & 439.5 & 40.4 & 454.6 & 1.4 \\
$50 / 5 / 50$ & 305.1 & 319.3 & 18.9 & 349.6 & 398.0 & 34.1 & 411.0 & 442.5 & 43.4 & 458.9 & 3.3 \\
20/80 & 318.2 & 319.09 & 8.6 & - & - & - & 346.8 & 440.6 & 90.6 & 458.9 & 0.7 \\
20/5/80 & 319.5 & 319.08 & 7.7 & - & - & - & 335.2 & 442.1 & 89.7 & 457.5
\end{tabular}

$T_{5}$ : temperature at which $5 \%$ weight loss occurs from the TG curve; $T_{1,2,3}^{\max }$, temperature of maximum rate of decomposition for the 1 st, $2 \mathrm{nd}$, and $3 \mathrm{rd}$ steps of degradation, respectively, from the DTG curve; $\Delta_{m 1,2,3}:$ mass loss on the end of the 1st, 2nd, and 3rd steps of degradation; $T^{i}$ : temperature of initial decomposition for the 2 nd and 3 rd steps of degradation; $T_{\text {end }}$ : final degradation temperature.

the addition of talc. Figure $3(\mathrm{~b})$ shows that the TPU/PP blends with talc (TPU/T/PP blends) exhibited a much greater exothermic crystallization peak. The peak temperature of the crystallization $\left(T_{\mathrm{cp}}\right)$, enthalpy of melting $\left(\Delta H_{m}\right)$ and enthalpy of crystallization $\left(\Delta H_{c}\right)$ was higher for talc filled TPU/PP blends than that of unfilled blends. The higher values of the degree of crystallinity $\left(\chi_{c}\right)$ for talc filled TPU/PP blends indicated that the talc acts as a nucleating agent $[13,14]$.

In order to determine the thermal stability of the neat polymers, composites and unfilled and talc filled TPU/PP blends thermogravimetric analysis (TGA) was used. The thermal stability of the investigated samples was determined in terms of $T_{5}$, temperature at which $5 \%$ weight loss occur. Figure 4 shows the TG curves (Figure 4(a)) and DTG curves (Figure 4(b)) of the unfilled and talc filled TPU and PP; the values of characteristic temperatures are shown in Table 3.
From the DTG curves obtained for the unfilled and talc filled TPU it was evident that the thermal degradation occurred in two steps of degradation. The first step of degradation is assigned to the degradation of the hard segment, while the second step is related to the degradation of the soft segments in TPU [15]. The results in Table 3 show that the first step of decomposition starts at $288.1^{\circ} \mathrm{C}$ for unfilled TPU (TPU $100 / 0$ ) and $295.0^{\circ} \mathrm{C}$ for talc filled TPU (TPU/T 100/5). In the first step of degradation a weight loss of $62.3 \%$ (TPU) and $33.4 \%$ (TPU/T) was observed with a maximum rate of weight lost $\left(T_{1}^{\max }\right)$ at 328.8 and $331.1^{\circ} \mathrm{C}$, respectively, while in the second step it lost $30.2 \%$ (TPU) and $53.4 \%$ (TPU/T) with $T_{2}^{\max }\left(368.8\right.$ and $\left.380.0^{\circ} \mathrm{C}\right)$ and the first step of degradation finished at $T_{\text {end }}\left(400.4\right.$ (TPU) and $\left.458.4^{\circ} \mathrm{C}(\mathrm{TPU} / \mathrm{T})\right)$. From the obtained results it can be concluded that the degradation of TPU takes place at temperatures from $288.1^{\circ} \mathrm{C}$ to $400.4^{\circ} \mathrm{C}$ 


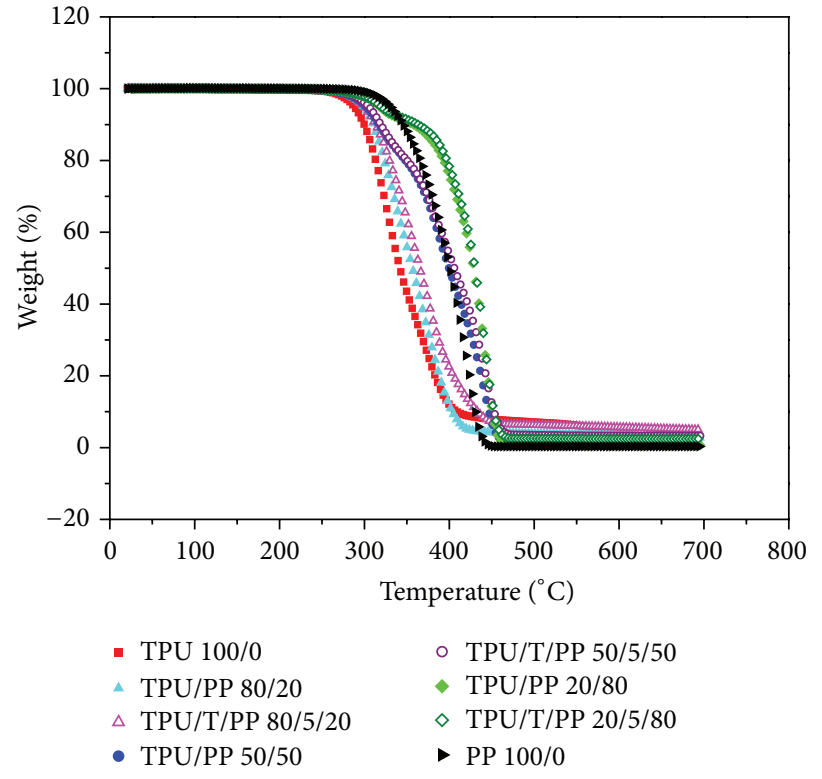

(a)

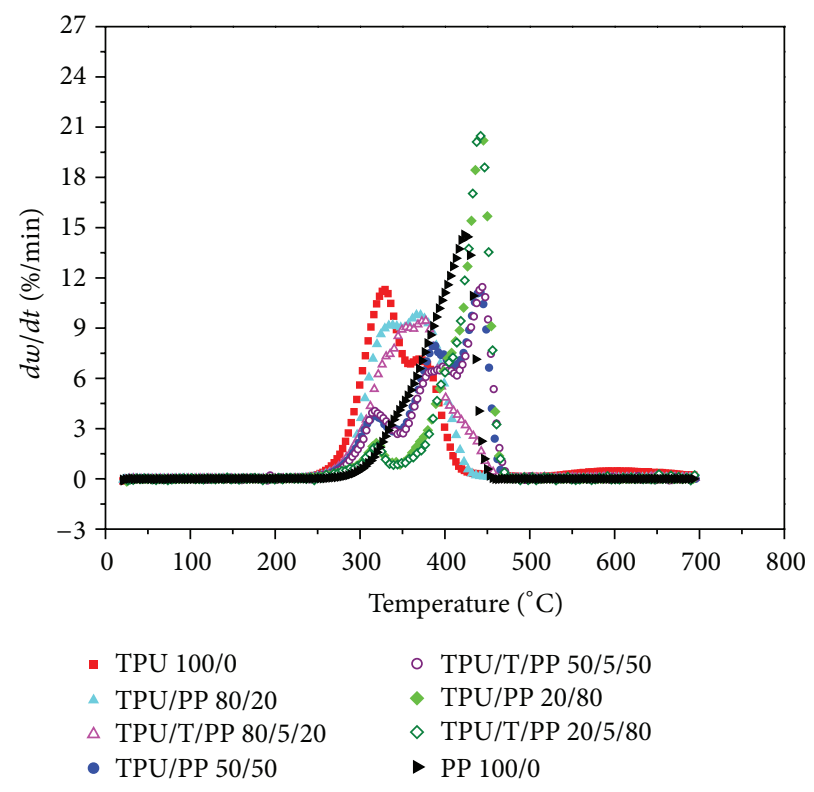

(b)

Figure 5: TG curves (a) and DTG curves (b) of the neat TPU, PP and unfilled and talc filled TPU/PP blends.

and for TPU/T from $295.0^{\circ} \mathrm{C}$ to $458.4^{\circ} \mathrm{C}$. The weight residues at the temperature of $700^{\circ} \mathrm{C}$ are $0.7 \%$ and $4.9 \%$, respectively.

One step of degradation was observed for the neat PP which started at $330.7^{\circ} \mathrm{C}$ with a maximum rate of weight lost $\left(T_{1}^{\max }\right)$ at $423.9^{\circ} \mathrm{C}$ and end set decomposition temperature $\left(T_{\text {end }}\right)$ at $437.7^{\circ} \mathrm{C}$. The PP lost $99.7 \%$ of its weight and the weight residue at $T=700^{\circ} \mathrm{C}$ is $0.3 \%$. Based on the obtained results it can be concluded that PP degrades faster than TPU, but decomposition starts at higher temperatures, which confirms its higher thermal stability. The thermal stability of talc filled PP increased compared with the neat PP.

Figures 5(a) and 5(b) represent TG and DTG curves of all investigated TPU/PP blends; the characteristic values related to the decomposition temperatures are shown in Table 3.

All blends display three degradation steps, the first and the second related to the degradation of the hard and soft segments in TPU, while the third to the degradation of PP. The $T_{5}$ for the TPU/T/PP: $80 / 5 / 20,50 / 5 / 50$, and $20 / 5 / 80$ are at $300.0,305.1$, and $319.5^{\circ} \mathrm{C}$ respectively, which are all greater than $288.1^{\circ} \mathrm{C}$ for the neat TPU and $299.6,301.7$, and $318.2^{\circ} \mathrm{C}$, respectively, for the unfilled TPU/PP blends. The results of $T_{5}$ suggest that the incorporation of talc into TPU and TPU/PP blends could improve the thermal stability of the blends. This is probably due to the good polymer-filler interaction. The residues of all talc filled TPU/PP blends were all larger than those of unfilled TPU/PP blends and decreased with the increase of PP content.

SEM micrographs of the cryogenically fractured samples indicated a two-phase morphology with no sign of interfacial adhesion. In the SEM micrograph of the 80/20 TPU/PP blend more black hollows were shown to have arisen from dispersed PP particles that were pulled out (Figure 6(a)). The smaller hollows can be observed in the SEM micrograph of the 20/80 TPU/PP blend (Figure 7(a)). The observed two-phase morphology of the TPU/PP blends indicated the immiscibility and low compatibility of the components. Since the immiscible blends are thermodynamically unstable, they must be stabilized to prevent coalescence during melt processing. The stability of polymer blends is enhanced by the addition of a useful block copolymer or filler. The influence of the talc on the TPU/PP blends is shown in Figures 6(b) and $7(\mathrm{~b})$, respectively. With the addition of talc, the relatively finer dispersity of the phases was found and the smaller hollows as well. So, in this case, the homogeneity of the blend is better than that of the blend without talc.

\section{Conclusion}

The thermal and morphology properties of neat components (TPU, PP) TPU/T and PP/T composites and TPU/PP blends were investigated by differential scanning calorimetry (DSC), dynamic mechanical analysis (DMA), thermogravimetric analysis (TGA), and scanning electron microscopy (SEM). In DMA results the presence of two $T_{g}$ 's in the blends which were shifted toward each other suggests that TPU/PP blends are partially compatible. The intensity of the glass transition peak of the amorphous phase of TPU decreased upon the addition of PP. This might be explained with a lower segmental mobility which is suppressed by the crystalline phase of PP. The DSC results indicated that a higher degree of crystallinity $\left(\chi_{c}\right)$ was obtained for TPU/PP blends when talc is added, which can be attributed to the nucleating effect induced by talc particles. This finding implies that the introduction of talc into TPU/PP blends improved compatibility of TPU and PP. According to the TGA results the thermal stability of talc filled TPU/PP blends was higher compared to the unfilled 


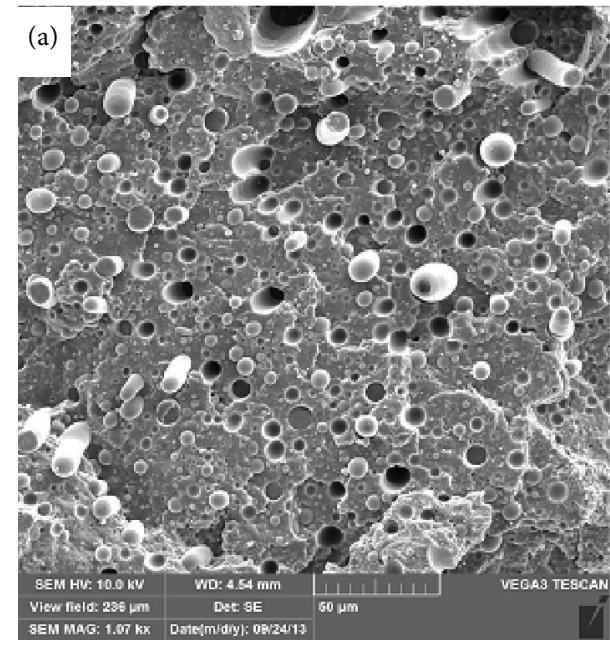

(a)

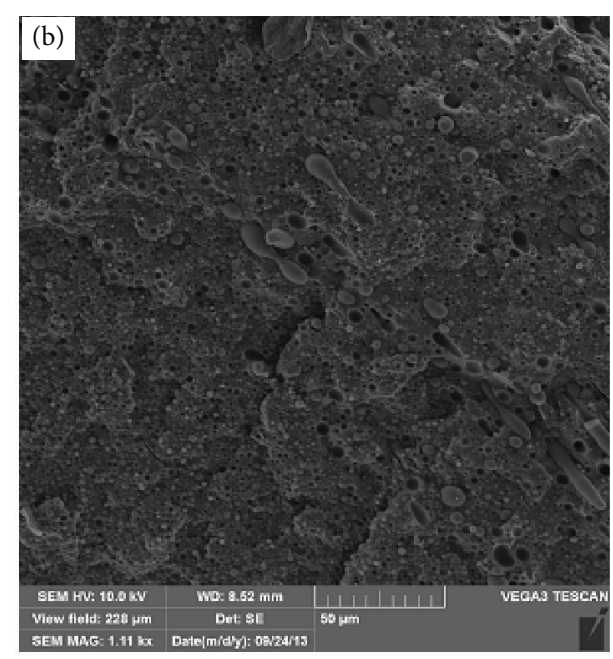

(b)

FIgURE 6: SEM micrographs of the TPU/PP $80 / 20$ blend (a) and 80/5/20 blend (b).

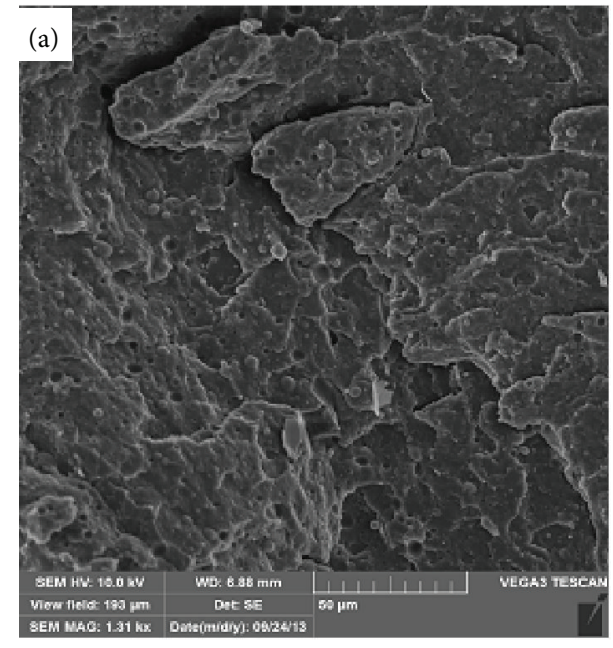

(a)

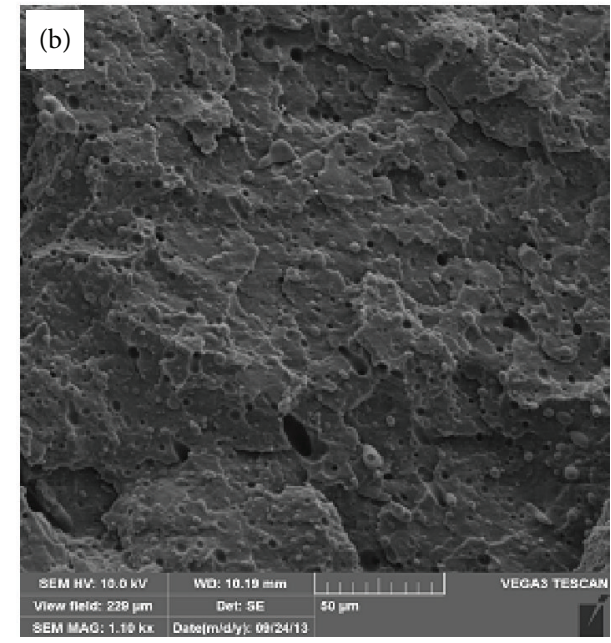

(b)

FIGURE 7: SEM micrographs of the TPU/PP 20/80 blend (a) and 20/5/80 blend (b).

TPU/PP blends. With the addition of talc, the relatively finer dispersity of the phases was found and the smaller hollows as well. The homogeneity of the talc filled TPU/PP blends is better than unfilled TPU/PP blends.

\section{Conflict of Interests}

The authors declare that there is no conflict of interests regarding the publication of this paper.

\section{Acknowledgment}

The authors gratefully acknowledge the financial support of this work by the Ministry of Science, Education and Sport of the Republic of Croatia (Project no. 125-1252971-2578).

\section{References}

[1] S. L. Cooper and A. V. Tobolsky, "Properties of linear elastomeric polyurethanes," Journal of Applied Polymer Science, vol. 10, pp. 1837-1844, 1966.

[2] B. Lotz, J. C. Wittmann, and A. J. Lovinger, "Structure and morphology of poly(propylenes): a molecular analysis," Polymer, vol. 37, no. 22, pp. 4979-4992, 1996.

[3] J. Varga, "Supermolecular structure of isotactic polypropylene," Journal of Materials Science, vol. 27, no. 10, pp. 2557-2579, 1992.

[4] B. Pukanszky, "Composites," in Polypropylene: Structure, Blends and Composites, J. Karger-Kocsis, Ed., vol. 3, pp. 1-70, Chapman \& Hall, London, UK, 1995.

[5] M. Fujiyama and T. Wakino, "Crystal orientation in injection molding of talc-filled polypropylene," Journal of Applied Polymer Science, vol. 42, no. 1, pp. 9-20, 1991. 
[6] B. Wunderlich, Crystal Structure, Morphology, Defects, Macromolecular Physics, Academic Press, New York, NY, USA, 1973.

[7] B. Wunderlich, Crystal Melting, Macromolecular Physics, Academic Press, New York, NY, USA, 1980.

[8] Y. Kim, W. J. Cho, and C. S. Ha, "Dynamic mechanical and morphological studies on the compatibility of plasticized PVC/thermoplastic polyurethane blends," Journal of Applied Polymer Science, vol. 71, no. 3, pp. 415-422, 1999.

[9] P. Potschke, K. Wallheinke, H. Fritsche, and H. Stutz, "Rheology modification of PVC plastisols with poly(butylene terephthalate)- $b$-poly(tetramethylene glycol)," Journal of Applied Polymer Science, vol. 66, no. 4, pp. 749-753, 1997.

[10] R. H. Boyd, "Relaxation processes in crystalline polymers: experimental behaviour-a review," Polymer, vol. 26, no. 3, pp. 323-347, 1985.

[11] B. E. Read, G. D. Dean, and P. E. Tomlins, "Effects of physical ageing on creep in polypropylene," Polymer, vol. 29, no. 12, pp. 2159-2169, 1988.

[12] D. Sudhin and J. L. David, Polymer Compatibilizers, Hanser Publishers, Munich, Germany, 1996.

[13] J. Menczel and J. Varga, "Influence of nucleating agents on crystallization of polypropylene. I: talc as a nucleating agent," Journal of Thermal Analysis, vol. 28, no. 1, pp. 161-174, 1983.

[14] J. Varga and F. Schulek-Tóth, "Filled compounds of the $\beta$ modification of polypropylene," Die Angewandte Makromolekulare Chemie, vol. 188, no. 1, pp. 11-25, 1991.

[15] H. K. Lee and S. W. Ko, "Structure and thermal properties of polyether polyurethaneurea elastomers," Journal of Applied Polymer Science, vol. 50, no. 7, pp. 1269-1280, 1993. 

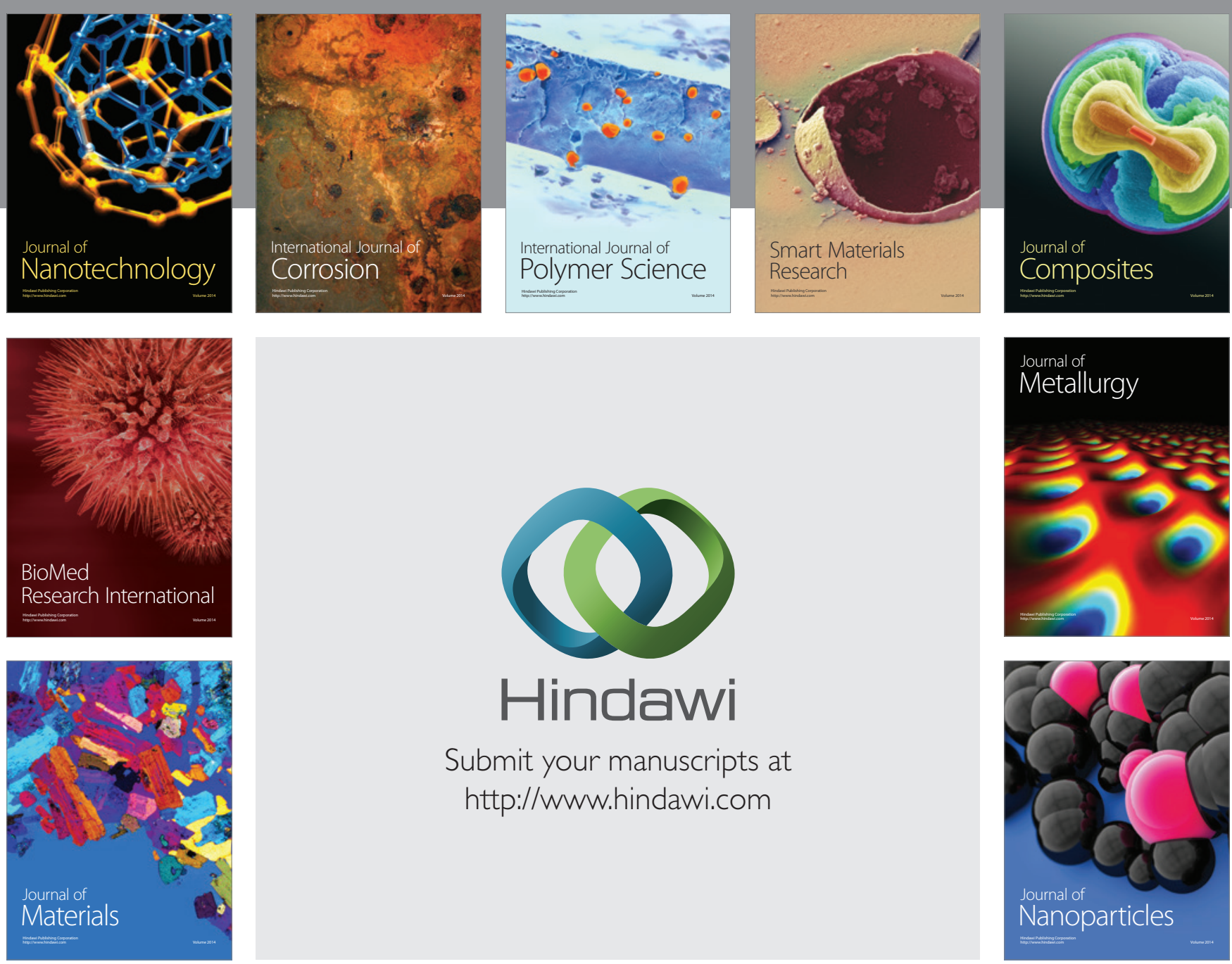

Submit your manuscripts at http://www.hindawi.com
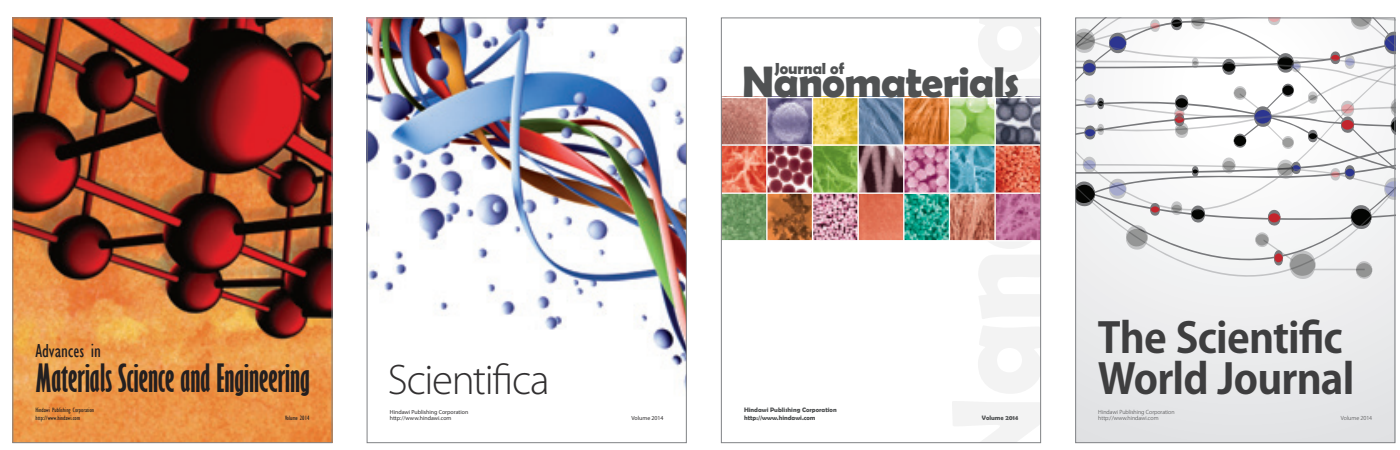

\section{The Scientific World Journal}
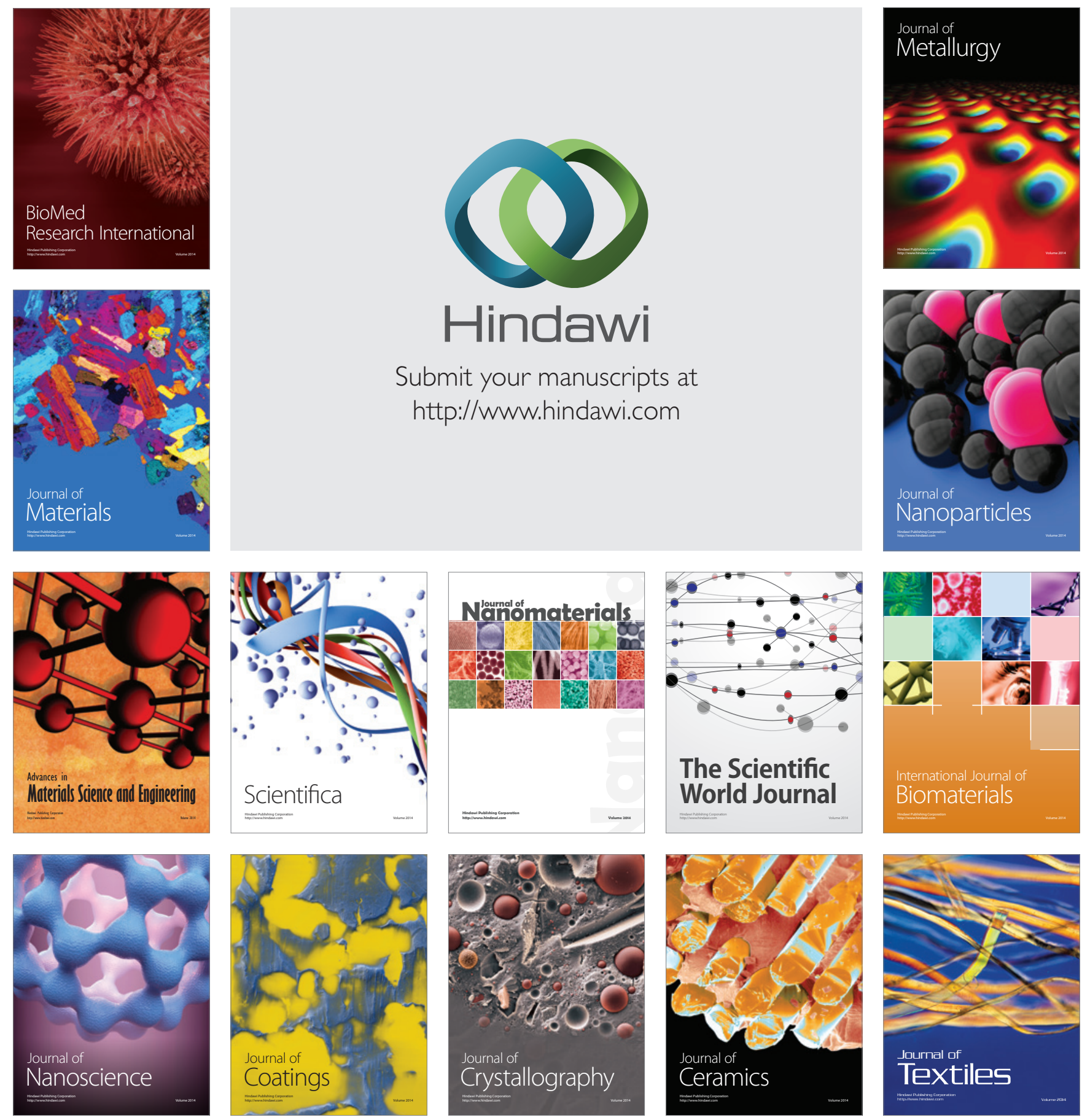